\title{
MEDIAÇÃO PEDAGÓGICA E EDUCAÇÃO MEDIADA POR TECNOLOGIAS DIGITAIS EM TEMPOS DE PANDEMIA
}

\author{
Lidiane Goedert ${ }^{1}$ \\ Klalter Bez Fontana Arndt²
}

\begin{abstract}
Resumo: Esse artigo apresenta reflexões em torno do processo de mediação pedagógica e educação mediada por tecnologias digitais em um momento histórico marcado por uma pandemia. As restrições necessárias para o enfrentamento da pandemia, dentre elas o isolamento social, têm levado instituições de ensino de todos os níveis, públicas e privadas, a adotarem metodologias de ensino visando a continuidade das aulas de modo não presencial. Para analisar esse contexto educacional pelo viés da mediação pedagógica, apresentamos o conceito de mediação pedagógica, com enfoque no papel mediador do professor e na mediatização de conteúdos e da comunicação por meio das tecnologias digitais. Esperamos que as reflexões em torno desse processo contribuam na análise de antigos e novos desafios educacionais da cultura digital em tempos de pandemia.
\end{abstract}

Palavras-chave: Mediação Pedagógica. Tecnologias Digitais. Pandemia.

\section{PEDAGOGICAL MEDIATION AND EDUCATION MEDIATED BY DIGITAL TECHNOLOGIES IN PANDEMIC TIMES}

Abstract: This article presents reflections on the process of pedagogical mediation and education mediated by digital technologies in a historic moment marked by a pandemic. The necessary restrictions to face the pandemic, including social isolation, have led educational institutions at all levels, public and private, to adopt teaching methodologies aiming at the continuity of classes in person. To analyze this educational context from the perspective of pedagogical mediation, we present the concept of pedagogical mediation, focusing on the mediating role of the teacher and on the media coverage of content and communication through digital technologies. We hope that the reflections on this process will contribute to the analysis of old and new educational challenges of digital culture in times of pandemic.

Keywords: Pedagogical Mediation. Digital Technologies. Pandemic.

\footnotetext{
${ }^{1}$ Doutora em Educação (UMinho). Professora Efetiva na Universidade do Estado de Santa Catarina (UDESC). Endereço Postal: Avenida Madre Benvenuta, 2007, Itacorubi, Florianópolis/SC, CEP: 88.035001. E-mail: lidiane.goedert@udesc.br. ORCID: 0000-0002-7665-871X

2 Douranda no Programa de Pós-Graduação em Educação (UFSC). Endereço Postal: R. Eng. Agronômico Andrei Cristian Ferreira, 240-432 - Carvoeira, Florianópolis/SC, CEP: 88040-000. E-mail: klalter.fontana@gmail.com. ORCID: 0000-0003-2536-0777
} 


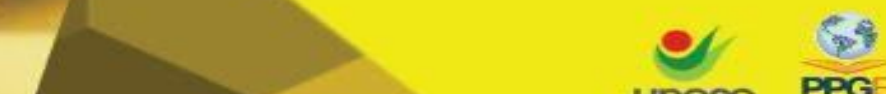 \\ unesc PPG

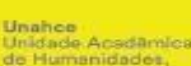 \\ Ciancias o Educang

Criar Educação, Criciúma, v. 9, n²2, Edição Especial 2020.- PPGE - UNESC - ISSN 2317-2452

\section{INTRODUÇÃO}

O ano de 2020 ficará marcado em nossa história contemporânea por uma pandemia provocada pelo novo coronavírus (SARS-CoV-2), que se alastrou e vem matando milhares de pessoas pelo mundo. Trata-se de um vírus que provoca uma doença respiratória aguda que pode levar ao óbito. O cenário que se desenha diante dessa pandemia é de incertezas, inseguranças e adaptações em todas as dimensões sociais, como na saúde, na política, na economia e na educação. No Brasil, o anúncio da pandemia aconteceu no mês de março de 2020 e veio acompanhado de medidas de restrição social (quarentena), exigindo ajustamentos dos vários setores da sociedade, dentre eles o da Educação que, pelas suas especificidades, foi um dos primeiros a ter suas atividades interrompidas.

No mês de março de 2020, o Ministério da Educação (MEC) autorizou as instituições de ensino superior, públicas e privadas, de todo o Brasil, a substituírem as aulas presenciais por aulas a distância (Portaria 343, de de 17 março de 2020; Portaria 544 , de 16 de junho de 2020) e liberou as escolas do cumprimento dos 200 dias letivos, embora mantenha a obrigatoriedade das 800 horas na educação básica (Medida Provisória 934, de $1^{\circ}$ abril de 2020). Ao mesmo tempo, tivemos como desdobramentos a publicação de resoluções estaduais e municipais com orientações específicas às suas redes de ensino.

Com a suspensão das aulas presenciais em todos os níveis de ensino, vários debates foram iniciados, buscando com eles compreender como as redes de ensino se adaptariam a essa nova realidade educacional que se desenhava. Muitos munícipios decidiram adiantar as férias de julho, enquanto decidiam sobre como dar continuidade às aulas; outras instituições já iniciaram com estratégias de atividades remotas, ou também chamadas de atividades pedagógicas não presenciais.

Diante desse contexto, o uso de tecnologias digitais e de metodologias características da Educação a Distância tem sido anunciado e colocado em prática por várias redes de ensino. $O$ ensino remoto ou online passou a vigorar em muitos municípios, seja pela oferta de aulas via plataformas digitais, por grupos de whatsapp 
Criar Educação, Criciúma, v. 9, n2, Edição Especial 2020.- PPGE - UNESC - ISSN 2317-2452

e/ou pela impressão de material escolar, entregues às famílias que não têm acesso à internet.

Esse cenário educacional totalmente novo obrigou educadores e gestores escolares a debaterem sobre a realidade educacional e a adotarem estratégias que pudessem ser substitutivas ao ensino presencial. Todo esse movimento teve como uma de suas pautas centrais a discussão sobre a mediação pedagógica via o uso de tecnologias digitais no processo de ensino e aprendizagem. Afinal, enquanto no ensino superior existe uma normativa que regulamenta a Educação a Distância, na educação básica essa era uma discussão ainda ausente ou bastante primária entre os educadores. Por conta disso, não é de estranhar o quanto as práticas de ensino remoto causaram desconfortos e receios entre todos os envolvidos na comunidade escolar.

São tantas as prerrogativas, que não faltam questões que nos levam a refletir sobre esse momento. Os professores foram convidados a participar do processo de definição das estratégias didático-metodológicas para a reposição/continuidade das aulas? Foi levado em consideração o contexto sócioeconômico dos alunos, bem como o acesso às redes digitais? Como o processo de mediação pedagógica, com componente online, tem sido concebido e acompanhado nas propostas implementadas pelas instituições de ensino em substituição às aulas presenciais? Como fica a formação docente frente aos novos desafios que se apresentam à Educação mediada por tecnologias digitais no cenário da pandemia? Quais os novos desafios apresentados? Como pensar em estratégias que não ampliem ainda mais o abismo das desigualdades sociais em nosso país?

Todo o processo para implantação do ensino remoto no contexto da Pandemia é novo, o que requer um olhar atento para as condições e particularidades que envolvem o uso das tecnologias digitais na educação. Embora vários e importantes debates estejam sendo realizados em torno desse cenário, o propósito deste artigo é fazer um recorte e contribuir, em especial, nas discussões sobre mediação pedagógica e educação mediada por tecnologias digitais. Assim, busca-se discutir o conceito de mediação pedagógica, destacando as especificidades desse processo quando o contexto de ensino e aprendizagem não é o presencial, ou seja, em 
contextos que envolvem o uso de tecnologias digitais para a proposição de atividades a distância, como o uso de ambientes virtuais, a realização de videoconferência e videoaula ou outras alternativas didático-metodológicas. Nesse sentido, aborda-se também o papel das tecnologias digitais na mediação pedagógica em tempo de pandemia e o papel do professor como mediador pedagógico online.

\section{MEDIAÇÃO PEDAGÓGICA E APRENDIZAGEM MEDIADA POR TECNOLOGIAS DIGITAIS}

O surgimento e o desenvolvimento das Tecnologias da Informação e Comunicação (TIC), especialmente as digitais, intensificou as possibilidades de acesso às informações, ampliou as formas de comunicação e modificou a relação humana com o ambiente profissional, acadêmico e familiar. Sobre a dimensão educacional, Jenkins (2009) observa que a sociedade contemporânea, caracterizada pela presença e influência das tecnologias digitais e mídias interativas, tem incitado professores e alunos a experiências de processos de ensino-aprendizagem que instigam a colaboração, a inovação, o compartilhamento e a coletividade.

As tecnologias digitais, entendidas aqui como artefatos culturais de nossa sociedade, contribuem para a ressignificação nas mais diferentes esferas da organização social, sejam elas culturais, políticas, econômicas ou educacionais. $\mathrm{Na}$ educação, a intensificação dos processos comunicativos e educativos transformou valores e diversificou as formas de relação com o saber (LÉVY, 2009). Sendo assim, concordamos com Goedert e Borges (2017), quando afirmam que as propostas didático-metodológicas em contextos educativos mediados por tecnologias digitais devem favorecer, dentre outros aspectos, o exercício cognitivo, a aproximação entre os sujeitos e o desenvolvimento de habilidades comunicativas. Entendemos que essa perspectiva exige análise criteriosa do processo de mediação pedagógica, tanto tecnológico quanto humano, necessário para que a aprendizagem se efetive.

No contexto brasileiro, as tecnologias digitais foram ressiginficadas e sua utilização potencializada. Tanto no convívio social, em que o isolamento e o distanciamento social foram adotados como fatores essenciais para evitar o contágio, quanto nos processos educacionais e laborais, as tecnologias digitais se tornaram artefatos essenciais em nosso cotidiano. Lives (de todo tipo e assuntos), aulas online, 
interações via redes sociais, canais de videoconferências, o digital se tornou um elemento central no nosso cotidiano, embora seja necessário frisar que o acesso não é democratizado. Na educação, a ausência de acesso à internet por uma parcela significativa da população, por exemplo, acaba sendo um fator que reforça e potencializa a exclusão que já antes existia. Isso é um aspecto sine qua non quando analisamos o contexto do ensino remoto na educação como um todo, em especial na educação básica.

No entanto, de forma geral, as instituições têm recorrido às estratégias do ensino online, comumente usadas na Educação a Distância $(\mathrm{EaD})$, para a continuidade da oferta dos processos educacionais. Assim, passamos a ter uma relação de mediatização via digital, que se torna uma ferramenta importantíssima nessa interface entre professores e alunos. Mas, inicialmente, é necessário fazermos algumas "limpezas" conceituais. Observamos que essas práticas de atividades não presenciais, denominadas de ensino remoto, online ou híbrido, estão sendo comumente chamadas de EaD. E sobre isso é necessário esclarecer que são práticas diferenciadas. No Brasil, a EaD é considerada uma modalidade educativa que posssui uma legislação própria. Toda instituição que a ofereça deve apresentar regulamentação e estruturação que legitime a sua oferta, hoje vista somente na educação superior. Os cursos ofertados a distância requerem uma proposta e uma arquitetura pedagógica que evidencie sua finalidade e tenha clareza de quem serão os sujeitos atendidos por ela.

O que as instituições escolares da educação básica estão oferecendo não é $\mathrm{EaD}$, mas um ensino que usa de estratégias e de metodologias que são próprios dessa modalidade. Tudo isso possibilitado por recursos oriundos do desenvolvimento tecnológico, que modifica a forma como a sociedade se organiza, como os processos são estabelecidos. Esse desenvolvimento tecnológico traz elementos para (re)pensarmos os processos educacionais tradicionais, mas sem esquecer a articulação necessária entre ensino e aprendizagem, e isso significa ter clareza de que ensinar é um processo totalmente diferente de educar. $O$ ensino sem a aprendizagem vira um processo inócuo, vazio. Por isso, faz-se necessário que as tecnologias sejam inseridas no planejamento pedagógico com um propósito 
educacional claro e que seja significativo aos sujeitos envolvidos. Não pode ser algo atropelado, feito de forma aligeirada para atender demandas de cumprimento de currículo.

Após esses esclarecimentos iniciais e necessários, consideramos pertinente refletir sobre como o processo de mediação pedagógica tem sido concebido e desenvolvido pelas instituições de ensino e pelos profissionais da educação que não estão habituados a desenvolver atividades educativas não presenciais e/ou mediadas por tecnologias digitais. Para fundamentar a análise, nos baseamos na concepção de Vygotsky sobre a organização adequada (intencional) do processo de aprendizagem. Goedert (2019) observa que ela se faz necessária ao desenvolvimento intelectual e mobiliza múltiplos processos de desenvolvimento que, de outra forma, seriam impossíveis de acontecer. Além disso, a autora ressalta que a mediação pedagógica na percepção de Vygotsky é um elemento decisivo e essencial no desenvolvimento intelectual, "sendo compreendida como ações realizadas no processo de interação entre o sujeito, o objeto da aprendizagem, outros sujeitos envolvidos e o próprio meio onde a experiência se realiza" (GOEDERT, 2017, p. 53).

Segundo os estudos sociointeracionias de Vygotsky, os sistemas simbólicos ou signos, como a linguagem, a escrita e o sistema numérico, assim como os sistemas de instrumentos, são criados pela sociedade ao longo do andamento da história humana e modificam a estrutura social e a condição de seu desenvolvimento cultural (MACHADO \& TERUYA, 2009; GOEDERT, 2017). São elementos culturais essenciais às interações e mediações que estabelecemos com o meio e com os outros.

Assim, o aprendizado perpassa necessariamente pelo processo de mediação pelo qual os sujeitos interagem (com os outros e com o meio) e se desenvolvem no ambiente sociocultural em que estão inseridos. De acordo com a teoria sociocultural de Vygotsky, as interações são a base para que o indivíduo consiga compreender (por meio da internalização) as representações mentais de seu grupo social - aprendendo, portanto. A construção do conhecimento ocorre primeiro no plano externo e social (com outras pessoas) para depois ocorrer no plano interno e individual. Nesse processo, a sociedade e, principalmente, seus integrantes mais experientes (adultos, em geral, e professores, em particular) são parte fundamental para a estruturação de 
que e como aprender. Essa compreensão das interações é essencial para não deslocarmos o conceito de mediação em Vygostky do seu contexto e para enterdermos a sua importância na ação educativa. Para que ocorra a internalização das atividades socialmente enraizadas e historicamente desenvolvidas (VYGOTSKY, 1988), a mediação passa a ser vista como um elemento essencial na educação, que vai atuar diretamente no nível de desenvolvimento potencial, ou seja, naquilo que o sujeito é capaz de aprender, só que mediante a interação com outras pessoas ou com o meio (incluindo aqui as tecnologias criadas).

A mediação, nessa perspectiva, é compreendida, portanto, como o processo de intervenção de um elemento intermediário (humano, instrumento ou simbólico) numa relação, em que esta deixa de ser direta e passa a ser mediada por esse elemento (VYGOTSKY, 1988). Tanto os signos quanto os instrumentos são considerados meios de intervenção na realidade e, por isso, são elementos mediadores. Nesse sentido, a noção de mediação de Vygotsky auxilia-nos na compreensão desse processo em contexto de ensino-aprendizagem online. Logo, podemos entender que, nesse cenário, os instrumentos e os signos relacionados à mediação pedagógica correspondem aos recursos tecnológicos, aos materiais didáticos, às linguagens, às formas de comunicação, ao conhecimento, ou seja, são ferramentas e formas de representação da realidade construídas socialmente e historicamente (GOEDERT, 2019).

A mediação pedagógica envolve necessariamente interações, seja entre os sujeitos envolvidos no processo, seja entre os sujeitos e os recursos, entre os sujeitos e o meio em que está inserido (MASETTO, 2003). E para que a mediação ocorra é preciso envolver diálogos, trocas de experiências, resoluções de problemas e desafios que levam os sujeitos a questionarem e a fazerem proposições para entender a situação apresentada. E como fazer com que todo esse movimento, essencial ao 


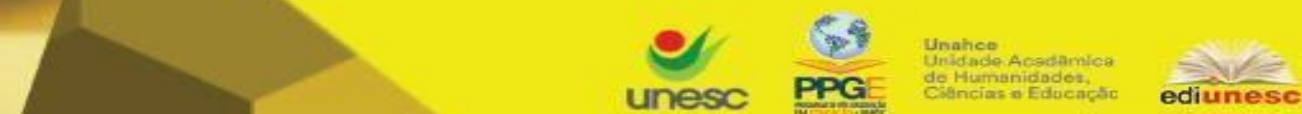

Criar Educação, Criciúma, v. 9, №2, Edição Especial 2020.- PPGE - UNESC - ISSN 2317-2452

aprendizado, ocorra por meio de atividades não presenciais? Sobre isso discorreremos um pouco mais a seguir.

\section{MEDIAÇÃO PEDAGÓGICA EM TEMPOS DE PANDEMIA: O PAPEL DO PROFESSOR EM FOCO}

Tendo por base o conceito de mediação anteriormente visto, podemos nos indagar sobre como a mediação vem sendo viabilizada em tempos de ensino remoto, ainda mais se considerarmos um contexto educacional em que as discussões em torno dessa temática ainda são incipientes. Se já não é simples realizar a mediação via tecnologias digitais em universidades, imaginamos como esse processo vem ocorrendo na educação básica, em especial na educação infantil e nos anos iniciais do ensino fundamental. Como mediar o processo educacional com crianças tão pequenas, numa etapa educacional em que a interação social é um dos principais elementos mediadores do desenvolvimento e do aprendizado? As crianças necessitam do meio social, do contato com seus pares, elementos para desenvolver sua autonomia e se perceber como um sujeito coletivo. Por outro lado, temos também os professores, que em geral não são preparados para exercer a docência via tecnologias digitais e que se viram, de forma abrupta, a terem que adequar todo seu planejamento para aulas online, gravação de vídeos ou simplesmente ter que orientar as famílias na mediação das atividades com as crianças. São questões que requerem análises cuidadosas sobre os desafios e possibilidades pedagógicas relacionados ao advento das mídias digitais.

O advento da mídia digital apresenta desafios ainda mais amplos para a escola enquanto instituição. Uma questão-chave, levantada por vários autores, concerne ao seu papel no enfrentamento das desigualdades de acesso à tecnologia surgida na sociedade. Acesso, neste sentido, é mais do que disponibilidade de equipamento, ou uma questão de habilidades técnicas: é também uma questão de capital cultural - a capacidade de usar formas culturais de expressão e comunicação. (BUCKINGHAM, 2010, p. 53)

O processo educacional, quando mediado por tecnologias digitais, exige do professor, acostumado ao cotidiano do ensino presencial, a imaginação criadora para atender às novas demandas sociais de aprendizagem interativa, na qual a mediação das TIC deixa de ser meramente instrumental para converter-se em ações que 


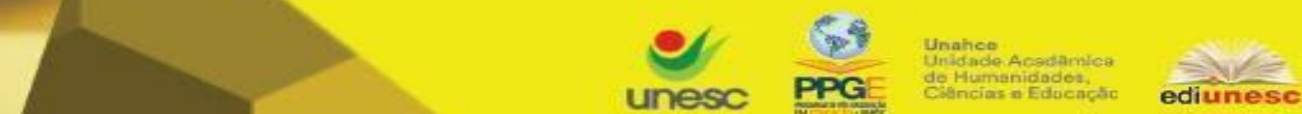

Criar Educação, Criciúma, v. 9, №2, Edição Especial 2020.- PPGE - UNESC - ISSN 2317-2452

possibilitem a expressão de sentimentos, de partilhas e de conhecimentos. Nessa perspectiva, os sujeitos envolvidos passam a ter a necessidade de desenvolverem outras racionalidades, ritmos de vida e relações com os objetos e com as pessoas (MARTÍN-BARBERO, 2008).

Mas, para que isso ocorra, não basta simplesmente usar os artefatos digitais; é necessário que estes sejam pensados numa perspectiva pedagógica e inseridos em um planejamento que leve em consideração a realidade em que vivem os sujeitos (neste caso, os alunos), a faixa etária e a etapa educacional em que estão inseridos. $E$ isso é complexo de se fazer, se levarmos em consideração a realidade das escolas públicas e a formação do professor para viabilizar todo esse processo (FANTIN, 2012; BELLONI, 2018).

Sendo assim, uma das atribuições do professor na proposição, desenvolvimento e mediação de atividades de aprendizagem com tecnologias digitais, diz respeito à necessidade de apropriação crítica dessas tecnologias.

Falar em apropriação das tecnologias no contexto das culturas digitais, hoje, envolve a construção de conhecimentos em diferentes linguagens (escrita, plástica, musical, audiovisual, digital) que possuem seus códigos e suas especificidades. Por sua vez, seus processos de aprendizagem são complexos, e envolvem conceitos e dimensões que se entrecruzam numa perspectiva de múltiplas linguagens ou multiliteracies. (FANTIN, 2012, p. 273)

Sobre o processo de apropriação tecnológica por professores, Goedert e Marcon (2017) observam que a heterogeneidade de ferramentas e potencialidades que surgem com a cultura digital, trazem desafios para os sistemas educativos e para os professores. Entretanto, a inserção desses recursos no processo de ensinoaprendizagem requer conhecimento tecnológico por parte dos professores, além do reconhecimento de suas possibilidades e potencialidades pedagógicas. Sendo assim, na perspectiva das autoras, a apropriação tecnológica por professores pressupõe o desenvolvimento de habilidades e conhecimentos sobre como utilizar (aspectos técnicos) e reconhecer as funcionalidades e limitações dos recursos disponíveis ou que estão sendo utilizados. 


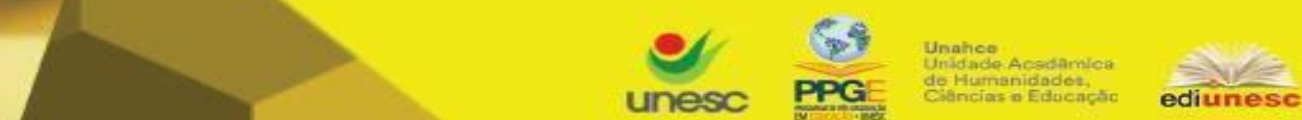

Criar Educação, Criciúma, v. 9, ํㅡ, Edição Especial 2020.- PPGE - UNESC - ISSN 2317-2452

Assim, entendemos que as propostas pedagógicas que envolvem o uso de tecnologias digitais precedam de uma percepção pedagógica sobre o potencial pedagógico dessas tecnologias e sobre as necessidades formativas dos professores em relação às particularidades de mediar pedagogicamente em processos educativos que envolvam comunicação mediatizada e interação online.

O professor, nesse sentido, continua sendo essencial no processo educacional, como agente mediador, mas que precisa ter clareza e saber como realizar essa mediação com crianças via tecnologias digitais. É fundamental não perdermos de vista que o elemento humano é condição sine qua non em todo esse processo de ensino remoto e/ou online e que as tecnologias são percebidas como artefatos que podem contribuir nesse processo.

\begin{abstract}
Em sua essência, ser professor hoje, não é nem mais difícil nem mais fácil do que era há algumas décadas atrás. É diferente. Diante da velocidade com que a informação se desloca, envelhece e morre, diante de um mundo em constante mudança, seu papel vem mudando, senão na essencial tarefa de educar, pelo menos na tarefa de ensinar, de conduzir a aprendizagem e na sua própria formação que se tornou permanentemente necessária. (GADOTTI, 2003, p. 15)
\end{abstract}

Mas, o que temos presenciado é uma formação deficiente dos professores para realizar essa mediação, muitas vezes online, diante de um cenário inesperado de pandemia. De repente, esses profissionais se viram obrigados a gravar aulas, adequar materiais didáticos, orientar famílias e interagir virtualmente com crianças, sendo que muitas vezes eles próprios não possuem familiaridade com drives online e plataformas virtuais. É importante considerar, ainda, que muitos professores possuem acesso limitado às tecnologias necessárias para promover tais atividades.

Além disso, temos a questão de exposição do professor, que agora vê seu material e suas falas extrapolando as salas de aula presenciais e sendo compartilhadas no mundo digital. Tudo isso gera insegurança, um elemento a mais de desestabilização dentro de um cenário epidemiológico que por si só já é bastante caótico. São muitos os especialistas realizando lives, prescrevendo o que o professor deve (ou não) fazer e quais os recursos digitais que pode utilizar para promover atividades não presenciais. São tantas expressões novas que o professor acaba se 
vendo num emaranhado conceitual e procedimental que o expõe ainda mais pedagogicamente, já não bastasse as dificuldades no manejo das ferramentas tecnológicas. A mediação, entendida como elemento central nesse contexto, acaba exigindo do professor competências que não estão claras ou que não foram desenvolvidas. Entretanto, embora esses desafios estejam postos, é consenso a importância da mediação docente no processo ensino-aprendizagem. E essa mediação vai muito além de ser um "lecionador para ser um organizador do conhecimento, um mediador do conhecimento, um aprendiz permanente, um construtor de sentidos, um cooperador e, sobretudo, um organizador de aprendizagem". (GADOTTI, 2003, p. 16)

Enfim, não podemos esquecer que o cenário de pandemia trouxe novos desafios para a educação e intensificou outros já existentes, pois estamos vivendo um cenário socioeconômico instável que tem contribuído para reforçar exclusões, como a educacional e digital. Entretanto, é importante considerarmos que o professor continua sendo um elemento mediador fundamental, no sentido de planejar e conduzir o processo educativo, mesmo diante de tantos desafios que se apresentam à educação em nosso país, dentre eles o de propor e mediar atividades de aprendizagem utilizando e explorando o potencial pedagógico das tecnologias digitais (MORAN; MASETTO, BEHRENS, 2013; BELLONI, 2018). Para fazer isso, é necessário que o professor se aproprie dessas tecnologias, ou seja, que seja capaz de utilizá-las e de explorá-las pedagogicamente. E essa apropriação deve ser fomentada desde a formação inicial, o que ainda vemos lacuna nesse sentido. Segundo Estevan e Salles (2018), a análise de 14 pesquisas de pós-graduação realizadas entre 2010 e 2015, que tinham como objetivo discutir a formação inicial dos professores envolvendo temáticas relacionadas às tecnologias digitais, mostrou que há um "silenciamento das tecnologias digitais na formação inicial de professores" (2018, p. 43), ou quando o fazem, ainda é de forma incipiente. Tudo isso reforça a necessidade de que o debate e a formação sobre o papel mediador do professor, via tecnologias digitais, seja cada vez mais fomentado nos espaços formativos. 


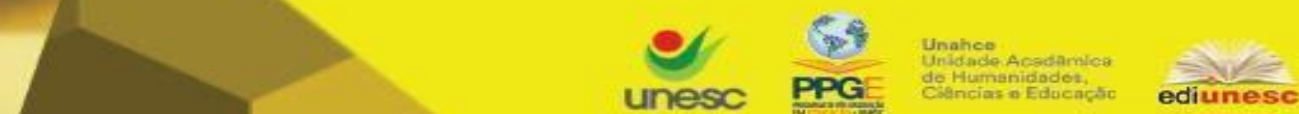

Criar Educação, Criciúma, v. 9, ํㅡ, Edição Especial 2020.- PPGE - UNESC - ISSN 2317-2452

\section{MEDIAÇÃo PEDAGÓGICA EM TEMPOS DE PANDEMIA: O PAPEL DAS TECNOLOGIAS DIGITAIS}

Atualmente, nossa cultura traz o digital como um de seus artefatos mais importantes, sendo ele um divisor de água na forma como as pessoas se relacionam, se comunicam, aprendem, enfim, trazendo impactos na organização social como um todo. Todas essas mudanças exigem que tenhamos uma atenção criteriosa e cuidadosa para essas nuances sociais.

A sociedade contemporânea, pautada pela cultura digital, modificou significativamente a forma como os sujeitos se organizam, interagem e se constituem no meio em que vivem. Ao mesmo tempo em que a cultura digital cria as condições para produção de novas identidades, "também são expressões delas, tanto no âmbito da cultura quanto das tecnologias, na medida em que põem em circulação estilos de vidas híbridos, metamórficos" (VENTURA; SOUZA; ARNDT; CRUZ, 2019, p. 34).

A importância das tecnologias digitais para a sociedade abre espaço para a reflexão sobre o papel que elas têm "desempenhado na contemporaneidade e na formação dos sujeitos" (FANTIN, 2011, p. 01). Segundo Lévy (2009), a cultura digital significa acesso à rede como um meio de comunicação, possibilitando que as pessoas possam aprender novas formas de se organizarem e viverem em sociedade. No entanto, é preciso ficarmos atentos para não sermos seduzidos pela visão de que a tecnologia é a salvação dos problemas existentes (visão integradora), nem chegar ao outro extremo e adotarmos uma visão apocalíptica da tecnologia (ECO, 1993).

O certo é que as análises dualistas sobre a comunicação na era das tecnologias digitais da informação - como Eco já apontava ao identificar os apocalípticos e integrados - revelam-se pouco esclarecedoras. As que surgem tentando estabelecer um pensamento teórico único, com categorias de totalidade, de validação geral e consensual, tendem a fracassar diante da complexidade do real. As que se apoiam na profusão de metáforas não colaboram para a precisão conceitual; confundem mais do que esclarecem a pretexto de provocar polêmica. Os que primam por fazer descrições que conduzem a previsões do futuro não permitem uma leitura real do presente e, talvez por isso, erram em suas profecias. Ao tentar fazer futurismo, alguns pesquisadores não percebem que, em termos de tecnologia digital, o futuro é o presente. (BIANCO, sd, p. 07) 


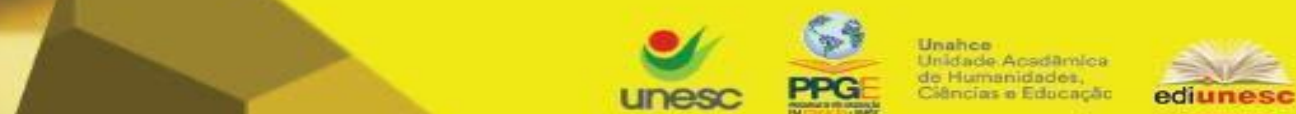

Criar Educação, Criciúma, v. 9, ํㅡ, Edição Especial 2020.- PPGE - UNESC - ISSN 2317-2452

Nessa perspectiva é possível compreender que a simples presença das tecnologias digitais não promove mudanças no processo educacional. As tecnologias podem potencializar o aprendizado, desde que estas sejam percebidas em suas potencialidades e integradas num planejamento educacional. Ensinar vai além da transmissão de um saber abstrato e descontextualizado. Isso significa dizer que o conhecimento se constrói na interação. Por isso, não é "um traço herdado ou ajuntado a ferro e fogo na memória" (D'ÁVILA, 2004, p. 264).

Um outro ponto importante ao se analisar as nuances da cultura digital para a educação, especialmente no Brasil, diz respeito ao acesso às tecnologias, ou seja, a inclusão digital.

Perpassando as ideias de Cazeloto (2009), pode-se dizer que há duas visões distintas ao relacionarmos democracia e internet: a primeira a respeito à igualdade de acesso a essas tecnologias, a qual o autor chama de "democratização da internet", enquanto a segunda diz respeito ao conceito de ciberdemocracia, considerada a "democratização pela internet". Embora havendo a noção dessa distinção, ainda hoje é possível observar que se prioriza a primeira visão, democratizando o acesso a hardwares e softwares, equipando escolas, sem genuína problematização daquilo que, de fato, está sendo democratizado. Nesse sentido, percebe-se que há a máscara da inclusão social, sem que se articulem demais elementos que de fato favoreçam trocas e oportunidades sociais, culturais ou mesmo econômicas. (HEINSFELD; PISCHETOLA, 2017, p. 1358)

Assim, a interconectividade, a interatividade e a descentralidade que as tecnologias digitais podem proporcionar passa pela forma como elas são democratizadas e integradas no cotidiano escolar, indo muito além da percepção de meros recursos instrumentais. O potencial mediador das tecnologias está relacionado diretamente com a forma como ela é percebida e inserida no planejamento pedagógico. Nesse cenário de ensino remoto, é importante termos essa acuidade ao olharmos as propostas que estão sendo implementadas, bem como a transposição que está sendo feita do conteúdo do presencial para o online. Video-aulas, uso de plataformas virtuais, canais no Youtube, blogs, redes sociais, enfim, são diversos os recursos digitais utilizados. Mas, o quanto essas novas "roupagens" contribuem para o aprendizado? Como as interações estão ocorrendo, como os debates estão acontecendo? Será que as tecnologias digitais estão facilitando a mediação pedagógica? E o que pensar das práticas que usam somente como canal de 
comunicação os drives e trocas de mensagens por aplicativos? São questões bastante complexas e precisamos ficar atentos para não cairmos na tentação de achar que essas tecnologias utilizadas são respostas aos problemas educacionais ou as que provocam esses problemas. Estamos sim, num momento atípico, em que muitas frentes estão sendo abertas para que o calendário escolar não pare. Mas é preciso uma reflexão se essas novas roupagens trazem em si mudanças efetivas. Podemos ter simplesmente velhas práticas revestidas de modernas tecnologias. O que deve ser visto é a concepção educacional que sustenta essas práticas e a necessidade de garantir a apropriação crítica das tecnologias pelo professor, fatores essenciais para analisar o potencial pedagógico das tecnologias digitais e como a sua inserção no processo educativo tem contribuído para gerar processos de inclusão e mediação.

\section{CONSIDERAÇÕES FINAIS}

Apesar de concordarmos com o caráter mediador das tecnologias digitais no processo de mediação pedagógica, entendemos que a interação do professor na educação mediada por tecnologias digitais é essencial (GOEDERT, 2019). Além disso, acreditamos que o sucesso do processo de ensino-aprendizagem, nas diferentes práticas educativas, depende, em grande parte, da concepção de educação que sustenta tais práticas e da apropriação tecnológica pelo professor, conforme descrevemos anteriormente. Consequentemente, as tecnologias devem ser pensadas e incorporadas ao processo de ensino-aprendizagem com este propósito, extrapolando o caráter instrumental que carregam para se constituírem em recursos didáticos promotores de aprendizagens. Nesse sentido, a incorporação das tecnologias digitais no planejamento docente requer objetivos educacionais bastante claros, de tal forma que a escolha de determinadas tecnologias seja decorrente de um processo de apropriação crítica.

A formação docente é outra dimensão necessária para darmos conta de desenvolver as competências requeridas do professor para gerar processos de ensino -aprendizagem eficientes em contextos de educação mediada por tecnologias digitais. 
A discussão sobre as tecnologias e sua relação com a educação precisa ser feita ainda na formação inicial e ter sua continuidade no cotidiano educacional. As instituições escolares precisam ser espaços de reflexões da própria prática, incluindo aqui a concepção que se tem das tecnologias, em especial, as digitais e suas potencialidades pedagógicas.

É importante considerar a qualidade do uso das tecnologias nos contextos educativos, uma vez que ela deve extrapolar a mera instrumentalização e demonstração de conteúdos pedagógicos, mas, sobretudo possibilitar uma leitura crítica do mundo e uma melhor compreensão do poder e do papel dos veículos de informação e comunicação (GOEDERT, 2019).

Sendo assim, precisamos usar da nossa sensibilidade e de nossa criticidade para analisarmos o momento em que estamos vivendo, procurando ponderar sobre as distintas propostas pedagógicas que estão sendo implementadas em substuição às aulas presenciais, como o que pode ser aprimorado, o que é excludente, o que integra e o que agrega. Entendemos que o cenário de pandemia exigiu que decisões fossem tomadas com certa rapidez, sem tempo suficiente para reflexões mais profundas e planejamentos coletivos e colaborativos. Além disso, muitas dessas decisões foram diretivas, sem que fossem deliberadas de forma democrática. Dentre as definições necessárias, as tecnologias digitais foram de imediato cogitadas como possibilidade para a continuidade/reposição das atividades de ensino presenciais em um país com lacunas visíveis relacionadas à inclusão digital e à formação de professores, aspectos essenciais para implementar atividades ou metodologias a distância.

Entendemos que as tecnologias digitais oferecem um leque de possibilidades pedagógicas para o desenvolvimento de atividades remotas ou a distância, já confirmadas por significativas metodologias adotadas na modalidade EaD. Por esse motivo, é importante destacar que não estamos ignorando todo o esforço que as instituições e profissionais da educação tem feito para contornar o cenário instável que a pandemia do novo Coronavírus trouxe à educação e outros setores. No entanto, não podemos ignorar que esse cenário trouxe desafios e acelerou processos importantes que exigem reflexões sobre as condições socioeconômica dos estudantes 


\section{CRIAR EDUCAČ̃̃}

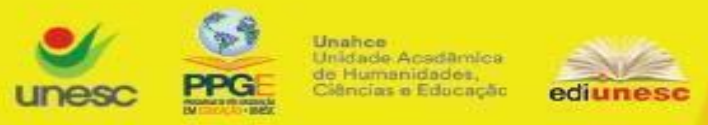

Criar Educação, Criciúma, v. 9, n²2, Edição Especial 2020.- PPGE - UNESC - ISSN 2317-2452

e sobre o papel das tecnologias digitais na educação de modo geral, especialmente na mediação pedagógica, uma dimensão essencial para que a aprendizagem se concretize.

Por fim, esperamos que as reflexões sobre as práticas pedagógicas implementadas com o uso de tecnologias digitais, visando a reposição das aulas presenciais interrompidas pela pandemia, assim como à continuidade dos processos de formação e educação, sirvam para superar antigos e novos desafios da cultura digital, gerar processos de decisão mais coletivos e colaborativos nas instituições de ensino e avaliar os distintos cenários socioeconômicos que perfazem a educação no Brasil.

\section{Referências}

BELLONI, M. L. Mídia-educação. In: MILL, D (Org.). Dicionário crítico de educação e tecnologias e de educação a distância. Campinas, SP: Papirus, 2018.

BIANCO, N. R. Del. Elementos para pensar as tecnologias da informação na era da globalização. Disponível em:

https://repositorio.unb.br/bitstream/10482/12173/1/ARTIGO_ElementosPensarTecnol ogias.pdf. Acesso em: 18 jun. 2020.

BRASIL. Ministério da Educação. Medida Provisória n. 934, de 1ª abril de 2020.

Ministério da Educação. Portaria n. 343, de 17 março de 2020.

Ministério da Educação. Portaria n. 544, de 17 junho de 2020.

BUCKINGHAM, D. Cultura digital, educação midiática e o lugar da escolarização.

Educação \& Realidade. Porto Alegre, v. 35, n. 3, set./dez. 2010. p. 37-58.

CAZELOTO, E. Apontamentos sobre a noção de "democratização da internet". In:

TRIVINHO, E., CAZELOTO, E. A cibercultura e seu espelho: campo de conhecimento emergente e nova vivência humana na era da imersão interativa. São Paulo: ABCiber; Instituto Itaú Cultural, 2009.

D'ÁVILA, C. Conhecimento compartilhado no espaço colaborativo das comunidades virtuais de aprendizagem. Revista da FAEEBA - Educação e contemporaneidade, Departamento de Educação, Salvador, v. 13, n. 22, p. 264-273, jun/dez. 2004.

ECO, U. Apocalípticos e integrados. $5^{\mathrm{a}}$ ed. São Paulo: Perspectiva, 1993. 
ESTEVAM, E. R.; SALES, S. R. Formação de professores e tecnologias digitais: levantamento e análise da produção discente na pós-graduação em educação. Revista Intersaberes, Curitiba, v.13, n. 28, p. 37-50, jan/abr. 2018.

FANTIN, M. Mídia-educação: aspectos históricos e teórico-metodológicos. Olhar de professor, Ponta Grossa, v. 14, n. 1, p. 27-40, 2011.

Dimensões da formação cultural e da mídia-educação na pedagogia.

EntreVer, Florianópolis, v. 2, n. 3, p. 264-280, jul/dez, 2012.

GADOTTI, M. Boniteza de um sonho: ensinar-e-aprender com sentido. Novo Hamburgo: Feevale, 2003.

GOEDERT, L. Práticas de mediação pedagógica online em interlocução com o modelo de comunidade de inquirição. Tese de Doutorado em Ciências da Educação (Especialidade Tecnologia Educativa). Instituto de Educação, Universidade do Munho, Portugal. Disponível em: http://repositorium.sdum.uminho.pt/handle/1822/64649. Acesso em 20 jun. 2020.

GOEDERT, L.; BORGES, M. K. Comunicação mediada por TIC: saberes, colaboração e conflito na aprendizagem online. In: XXIII Colóquio da AFIRSE/As pedagogias na sociedade contemporânea - Desafios às escolas e aos educadores, Lisboa: AFIRSE. EDUCA/Secção Portuguesa da AFIRSE, v. 1, p. 1-10, 2017.

GOEDERT, L.; MARCON, K. Tecnologias digitais de rede e formação de educadores: a percepção dos estudantes sobre seu processo formativo. Revista de Estudios e Investigación En Psicología y Educación, Vol. Extr., n. 13, 2017. Disponível em: http://revistas.udc.es/index.php/reipe/article/view/reipe.2017.0.13.2413/pdf. Acesso em 20 jun. 2020.

HEINSFELD, B. D.; PISCHETOLA, M. Cultura digital e educação, uma leitura dos Estudos Culturais sobre os desafios da contemporaneidade. Revista lberoAmericana de Estudos em Educação, Araraquara, v. 12, n. esp. 2, p. 1349-1371, ago/2017.

JENKINS, H. Cultura da convergência. Trad. De Susana Alexandria. $2^{\mathrm{a}}$ ed. São Paulo: Aleph, 2009.

LÉVY, Pierre. Cibercultura. São Paulo: Editora 34, 2009.

MACHADO, S. F.; TERUYA, T. K. Mediação pedagógica em ambientes virtuais de aprendizagem: a perspectiva dos alunos. In: IX Congresso Nacional De Educação - EDUCERE e o III Encontro Sul Brasileiro De Psicopedagogia - ESBPABPp, PUCPR, Paraná, out. 2009. Disponível em: http://www.portugues.seed.pr.gov.br/arquivos/File/ead/suelen.pdf. Acesso em 20 jun. 2020.

MASETTO, M. T. Competência pedagógica do professor universitário. São Paulo: Summus, 2003. 


\section{CRIAR EDUCAÇÃO}

Revista do Programa de Pós-Graduação em Educação - UNESC

Criar Educação, Criciúma, v. 9, №2, Edição Especial 2020.- PPGE - UNESC - ISSN 2317-2452

MARTÍN-BARBERO, J. Dos meios às mediações: comunicação, cultura e hegemonia. 5ed. Rio de Janeiro: UFRJ, 2008.

MORAN, J.; MASETTO, M. T. BEHRENS, M. A. Novas tecnologias e mediação pedagógica. $21^{\underline{a}}$ ed. Campinas/SP: Papirus, 2013.

VENTURA, L.; SOUZA, T. E. de; ARNDT, K. B. F; CRUZ, D. M. Multiletramento e produção de identidade na sociedade contemporânea: analisando enunciados multimodais. In: Educação e tecnologias: experiências, desafios e perspectivas 4.1를 ed. Ponta Grossa/PR: Atena Editora, v.4, p. 33-47, 2019.

VYGOTSKY, L.S. A formação social da mente. $6^{\underline{a}}$ ed. São Paulo: Martins Fontes, 1988. 